\title{
Condensed Tannins from the Bark of Guazuma ulmifolia Lam. (Sterculiaceae)
}

\author{
Gisely C. Lopes, ${ }^{a}$ Juliana C. B. Rocha, ${ }^{a}$ Glalber C. de Almeida ${ }^{b}$ and João C. P. de Mello ${ }^{* a}$ \\ ${ }^{a}$ Programa de Pós-graduação em Ciências Farmacêuticas, Universidade Estadual de Maringá, \\ Av. Colombo, 5790, 87020-900 Maringá-PR, Brazil \\ ${ }^{b}$ Acadêmico de Farmácia, Universidade Estadual de Maringá, Av. Colombo, 5790, 87020-900 Maringá-PR, Brazil
}

\begin{abstract}
Das cascas de Guazuma ulmifolia Lam. (Sterculiaceae) foram isolados e identificados nove compostos: ent-catequina, epicatequina, ent-galocatequina, epigalocatequina, epiafzelequina$(4 \beta \rightarrow 8)$-epicatequina, epicatequina- $(4 \beta \rightarrow 8)$-catequina (procianidina B1), epicatequina- $(4 \beta \rightarrow 8)$ epicatequina (procianidina B2), epicatequina- $(4 \beta \rightarrow 8)$-epigalocatequina, e a nova substância 4'-O-metil-epiafzelequina. Suas estruturas foram elucidadas com base nos dados espectrais e da literatura. A "impressão digital" de um extrato semipurificado por cromatografia líquida de alta eficiência foi realizada em coluna $\mathrm{C} 18$, com uma mistura de acetonitrila $(0,05 \%$ de ácido

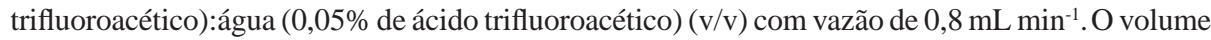
injetado da amostra foi de $100 \mu \mathrm{L}$ e o comprimento de onda $210 \mathrm{~nm}$.
\end{abstract}

From the bark of Guazuma ulmifolia Lam. (Sterculiaceae), nine compounds were isolated and identified: ent-catechin, epicatechin, ent-gallocatechin, epigallocatechin, epiafzelechin- $(4 \beta \rightarrow 8)$ epicatechin, epicatechin- $(4 \beta \rightarrow 8)$-catechin (procyanidin B1), epicatechin- $(4 \beta \rightarrow 8)$-epicatechin (procyanidin B2), epicatechin- $(4 \beta \rightarrow 8)$-epigallocatechin, and the new compound 4'- $O$-methylepiafzelechin. Their structures were elucidated on the basis of spectral and literature data. HPLC fingerprint analysis of the semipurified extract was performed on a C18 column, with a mixture of acetonitrile $(0.05 \%$ trifluoroacetic acid):water $(0.05 \%$ trifluoroacetic acid) $(\mathrm{v} / \mathrm{v})$ with a flow rate of $0.8 \mathrm{~mL} \mathrm{~min}^{-1}$. The sample injection volume was $100 \mu \mathrm{L}$ and the wavelength was $210 \mathrm{~nm}$.

Keywords: Guazuma ulmifolia, condensed tannins, HPLC, fingerprint

\section{Introduction}

Despite extensive destruction, it is believed that the rainforests still preserve 30 million individual species, roughly half of all life forms on earth and $2 / 3$ of all plants, without mentioning the importance of these forests to the earth's weather and atmosphere. In South America, the Amazon tropical forest covers approximately 665 million hectares, of which $60 \%$ lies within Brazil, covering $59 \%$ of the country's territory, in nine states: Acre, Amapá, Amazonas, Maranhão, Mato Grosso, Pará, Rondônia, Roraima and Tocantins. ${ }^{1}$

The importance of conserving the Amazon tropical forest is not limited only to the animal and plant species themselves, but also to the rich knowledge of the local people about the use of medicinal plants. Their knowledge stems as much from the necessity for alternative treatments

*e-mail: mello@uem.br because of low purchasing power and the difficulty of access to medical assistance, as from the profound cultural influence of the indigenous peoples of the region.

It is known that rapid social, cultural and economic changes strongly affect local knowledge of how to use natural resources. The problems stemming from this cultural loss are irreversible, and this loss reduces the possibilities of sustainably developing a region based on local experience. ${ }^{2}$

The discussion of alternatives for development and their relationship with the productive use of biodiversity is recent in Brazil. A proposal for sustainable development seeks to ally the need to protect the environment with the principal of equity with present and future human generations, through effective inclusion of the environment in socioeconomic decisions. However, it is no simple matter to develop a strategy that requires many solutions acting in parallel, including the demarcation of forest preserves, projects for renewable forest harvesting, and domestication 
of local species of economic importance, envisaging local productive networks. Thus, surrounding the interest in biodiversity are many economic, ecological, ethical and heritage factors. ${ }^{3}$

In this context, many endemic and non-native plant species in Amazonia have been studied scientifically, taking into consideration the knowledge of the local population, with a view toward obtaining new phytotherapeutic and cosmetic pharmaceuticals. ${ }^{4-9}$

Guazuma ulmifolia Lam. is a middle-sized tree, belonging to the family Sterculiaceae, which occurs naturally throughout Latin America. ${ }^{10}$ In Brazil, where it is popularly known as mutamba, this species extends from the Amazon region to the state of Paraná. ${ }^{11}$ It is pantropical, semideciduous, heliophytic, a pioneer, and is characteristic of second-growth broad-leaf forests. In Brazil, G. ulmifolia has been studied for its important role for the recovery of degraded areas..$^{10,11}$

In popular medicine, G. ulmifolia is traditionally used in several countries including Brazil, ${ }^{12}$ Guatemala,,${ }^{13-15}$ Haiti, ${ }^{16}$ Mexico, ${ }^{17-19}$ and Belize ${ }^{20}$ to treat bronchitis, burns, diarrhea, asthma, inflammations, and alopecia.

Previous investigations of the chemical composition of G. ulmifolia have indicated the occurrence of flavan-3-ols, procyanidins, ${ }^{21}$ and the nitrile glucoside menisdaurin. ${ }^{22}$ The anti-diabetic properties, ${ }^{23}$ hypotensive and vasorelaxant activity, ${ }^{24}$ antiulcer, ${ }^{25,26}$ anti-bacterial activities, ${ }^{20,27}$ and antiviral activity ${ }^{28}$ of the bark, aerial parts, fruits, crude extract, and fractions were attributed to the presence of proanthocyanidins.

The aim of the present study was to investigate the chemical profile of the bark of Guazuma ulmifolia Lam., to develop a HPLC-UV fingerprint and characterize its major active chemical constituents.

\section{Results and Discussion}

The ethyl acetate-soluble fraction obtained from the aqueous acetone extract of the air-dried bark was chromatographed on a Sephadex LH-20 column. Fractions containing proanthocyanidins were further purified by multi-layer-coil counter-chromatography (MLCCC) to give known and some rare compounds including ent-catechin (1), epicatechin (2), ent-gallocatechin (3), epigallocatechin (4), epiafzelechin- $(4 \beta \rightarrow 8)$-epicatechin $(5)$, epicatechin- $(4 \beta \rightarrow 8)$-catechin (PB1) (6), epicatechin$(4 \beta \rightarrow 8)$-epicatechin (PB2) (7) and epicatechin- $(4 \beta \rightarrow 8)$ epigallocatechin $(\mathbf{8})$. These were readily identified by comparison of spectroscopic data of the peracetates $\left({ }^{1} \mathrm{H}\right.$ NMR, ESI-MS, $\left.[\alpha]_{\mathrm{D}}^{20}\right)$ with authentic material..$^{29-37}$ The new compound 4'-O-methyl-epiafzelechin (9), discussed below, was established by physical properties $\left[{ }^{1} \mathrm{H}\right.$ NMR, ESI-MS, $\left.[\alpha]_{\mathrm{D}}^{20}\right]$ of the corresponding peracetate derivative.

Compound (9a) was visualized as a blue spot by spraying with $\mathrm{FeCl}_{3}$ reagent and showed a parent ion at $m / z 437.5[\mathrm{M}+\mathrm{Na}]^{+}$in the ESI-mass spectrum of the corresponding peracetate, suggesting a monomeric flavan3-ol. The ${ }^{1} \mathrm{H}$ NMR spectral $\left(\mathrm{CDCl}_{3}\right)$ data showed one three-proton singlet at $\delta 3.89$, indicating a methoxyl group. All heterocyclic protons could readily be assigned from the ${ }^{1} \mathrm{H}-{ }^{1} \mathrm{H}-\mathrm{COSY}$ spectrum. The compound showed a specific rotation of $-30^{\circ}$, and showed the typical spin systems of a 4',5,7-trihydroxyflavan-3-ol framework, i.e., a two-spin $\mathrm{AB}$-system for the A-ring, a four-spin $\mathrm{AA}^{1} \mathrm{BB}^{1}$-system for the B-ring, and a four-spin AMXY-system for the protons of the heterocyclic ring. The 2,3-cis relative configuration was evident from the ${ }^{3} J_{2,3}$ value of $c a .1 .0 \mathrm{~Hz}$ for the broadened 2-H resonance at $\delta$ 5.12. The circular dichroism (CD) spectrum in methanol exhibited a highamplitude negative Cotton effect at $280 \mathrm{~nm}$ for the ${ }^{1} \mathrm{~L}_{\mathrm{b}}$ transition and a positive Cotton effect at $240 \mathrm{~nm}$ for the ${ }^{1} \mathrm{~L}$ transition, hence unequivocally indicating a $2 R, 3 R$ absolute configuration and confirming the structure of compound (9) as 4'-O-methyl-epiafzelechin from the natural source. This compound is described here for the first time.

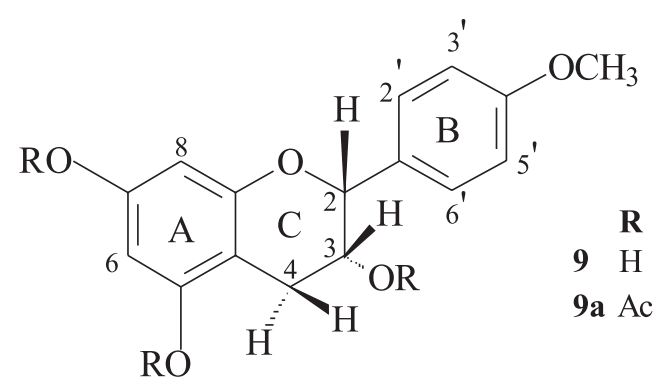

An HPLC fingerprint method developed for Guazuma ulmifolia can be conveniently employed for quality-control analysis. The experimental conditions chosen were those giving the most chemical information about the herbal medicine in the chromatograms. The column, mobile phase, detection wavelength, and conditions for gradient elution were all investigated.

The chromatographic separations were performed on a C18 analytical column, according to published methods. ${ }^{38,39}$ To obtain good separation, acetonitrile-water and methanolwater, both containing acid, were investigated as mobile phases. With methanol-water the peaks of compounds $\mathbf{6}$ and 7 always coeluted. More compounds were separated by the use of acetonitrile-water containing $0.05 \%$ trifluoroacetic acid. To obtain chromatograms with good 
resolution of adjacent peaks, different flow rates $(0.6,0.8$, and $0.9 \mathrm{~mL} \mathrm{~min}^{-1}$ ) were also investigated. Good separation

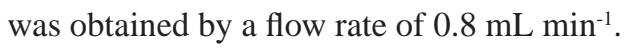

The elimination of high-molar-mass phenolic compounds from the plant extract is critically important, because of the interaction of these compounds with the stationary phase. This interaction can seriously damage the analytical column, interfering with the chromatographic process. Currently, the most widely employed samplepreparation methodologies are solid-phase extraction and liquid-liquid extraction. Therefore, in this study, the extraction of proanthocyanidin compounds from $G$. ulmifolia was optimized by using a mixture of water:ethyl acetate. The utilization of the simple one-step liquid-liquid extraction method should completely extract the target constituents from the matrix. The extraction efficiency was evaluated by HPLC, and the results demonstrated the reliability of the process.

The choice of detection wavelength is a crucial step in developing a reliable fingerprint. A UV detector was used in the current study. The spectra of all the main peaks were investigated by use of the diode-array detector, and $210 \mathrm{~nm}$ was selected as the detection wavelength to obtain a sufficiently large number of detectable peaks in the chromatograms. Figure 1 shows the chromatograms of the sample solution at 210 and $280 \mathrm{~nm}$. Comparing the absorbances at the two wavelengths, the absorbances at
$210 \mathrm{~nm}$ were higher than those at $280 \mathrm{~nm}$ for all compounds in the system. Thus, chromatograms recorded at $210 \mathrm{~nm}$ showed considerable improvement in the signal-to-noise ratio.

The total analysis time for each run was $32 \mathrm{~min}$. Good separations with a short run time were observed (Figure 2). The system suitability results are given in Table 1 .

Method precision was based on replicated analyses of samples, with reported relative standard deviations (RSD) less than 5\% for relative retention times (RRT) and relative peak areas (RPA) of all peaks. The reproducibility of the method was assessed by means of six replicated sample solutions extracted from a single batch of G. ulmifolia. The corresponding RSD of RRT and RPA were less than $5 \%$ over the investigation. The stability test was performed with a sample solution left to stand for $24 \mathrm{~h}$. The results obtained in the study of the solution (both time zero and the sample solution after $24 \mathrm{~h}$ ) indicated that the solutions were stable for $24 \mathrm{~h}$, because during this time the areas of the peaks did not decrease below a minimum percentage of $90 \%$ of the initial area. The data were assessed by Student's $t$ test and ANOVA, and showed no significant differences $(p<0.05 \%)$. The results showed that the method developed is a straightforward, sensitive, and selective tool with good accuracy and reproducibility, which can be readily utilized as a suitable method for quality control of G. ulmifolia.

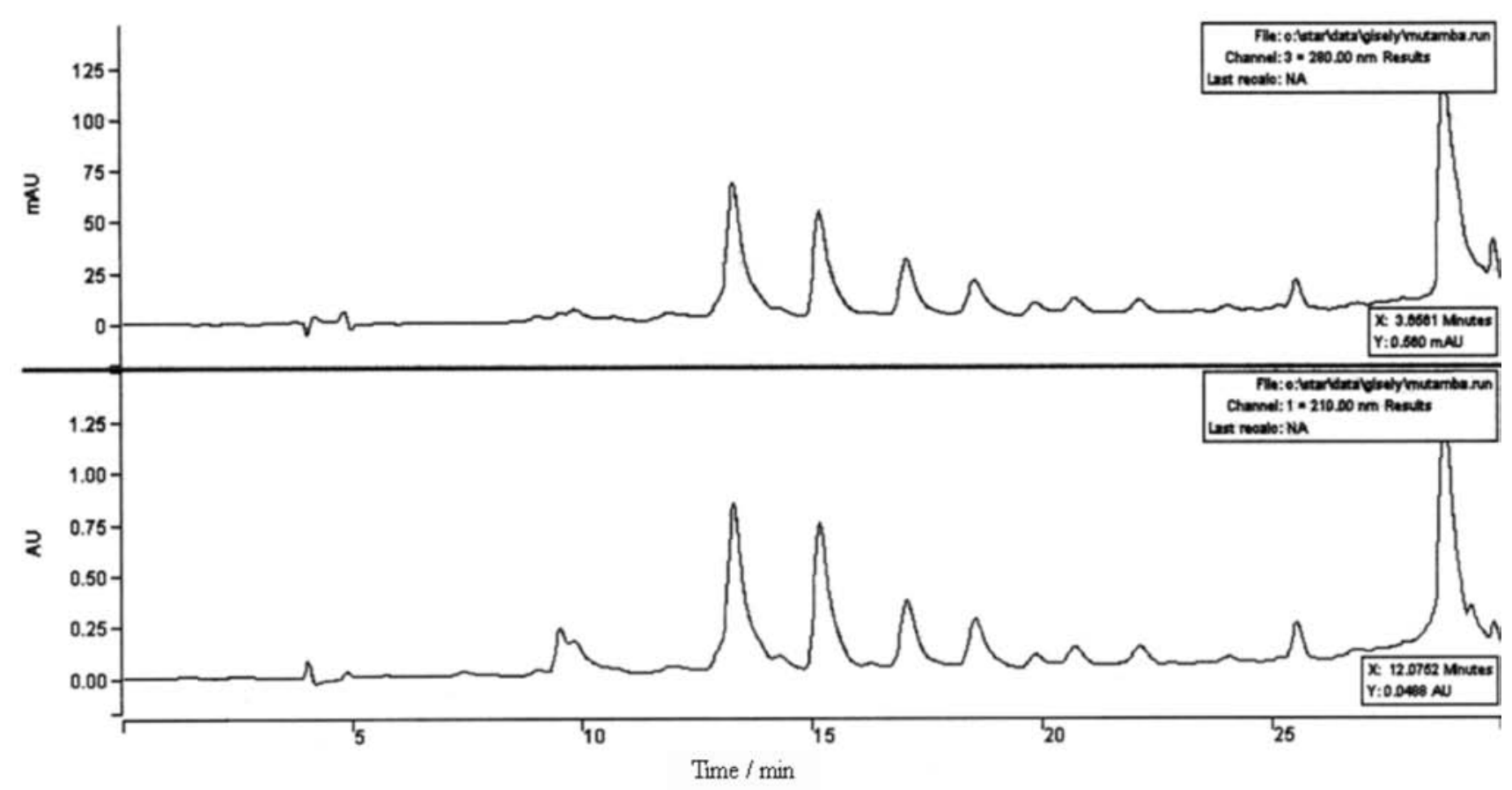

Figure 1. Chromatograms of G. ulmifolia with different extract UV detection methods at 210 and $280 \mathrm{~nm}$. 


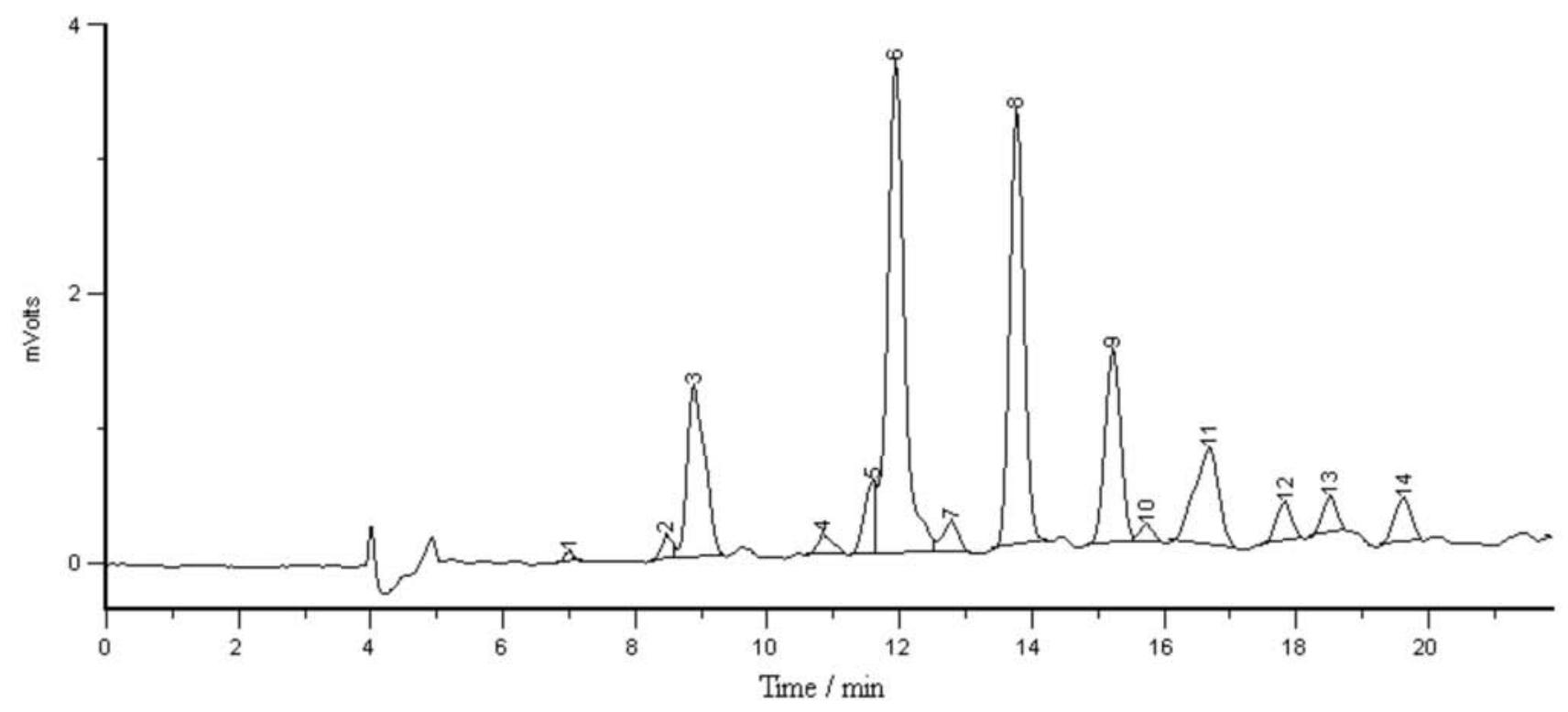

Figure 2. Standardized chromatographic fingerprint. Column: Phenomenex ${ }^{\circledast}$ Gemini RP C-18; flow rate: $0.8 \mathrm{~mL} \mathrm{~min}^{-1}$; detection: $210 \mathrm{~nm}$; temperature: $28^{\circ} \mathrm{C}$.

Table 1. System suitability test results $(\mathrm{n}=12)$

\begin{tabular}{|c|c|c|c|c|c|c|c|}
\hline Peak & $\begin{array}{l}\text { RSD of RT } \\
(\%)\end{array}$ & $\begin{array}{c}\text { RSD of area } \\
(\%)\end{array}$ & $\begin{array}{c}\text { Retention Factor } \\
(k)\end{array}$ & $\begin{array}{l}\text { Separation Factor } \\
\qquad(\alpha)\end{array}$ & Peak Resolution & Plates & Peak Asymmetry \\
\hline 1 & 2.72 & 4.54 & 1.76 & 1.76 & 4.170 & 9329 & 2.07 \\
\hline 2 & 1.95 & 4.91 & 2.13 & 1.21 & 0.72 & 7320 & 0.68 \\
\hline 3 & 2.97 & 1.72 & 2.22 & 1.04 & 2.85 & 4447 & 1.88 \\
\hline 4 & 2.47 & 4.60 & 2.70 & 1.22 & 1.53 & 7706 & 1.86 \\
\hline 5 & 2.03 & 4.28 & 2.92 & 1.08 & 0.56 & 19335 & 0.33 \\
\hline 6 & 2.25 & 3.75 & 2.99 & 1.02 & 1.16 & 12357 & 1.01 \\
\hline 7 & 2.14 & 4.94 & 3.19 & 1.07 & 1.38 & 10462 & 1.09 \\
\hline 8 & 2.01 & 1.62 & 3.44 & 1.08 & 1.93 & 19282 & 1.12 \\
\hline 9 & 2.15 & 2.11 & 3.79 & 1.10 & 0.88 & 18695 & 1.12 \\
\hline 10 & 1.59 & 3.27 & 3.93 & 1.04 & 1.31 & 20501 & 1.55 \\
\hline 11 & 1.47 & 1.28 & 4.16 & 1.10 & 1.37 & 8643 & 0.59 \\
\hline 12 & 1.75 & 3.64 & 4.44 & 1.07 & 1.14 & 22725 & 1.19 \\
\hline 13 & 1.72 & 4.37 & 4.62 & 1.04 & 1.83 & 30473 & 1.00 \\
\hline 14 & 1.57 & 4.84 & 4.92 & 1.06 & 4.91 & 22312 & 1.14 \\
\hline Reference $\mathrm{ICH}^{40}$ & - & - & $>2$ & $>1$ & $>2$ & $>2000$ & $\leq 2$ \\
\hline
\end{tabular}

\section{Experimental}

\section{Plant material}

Bark of Guazuma ulmifolia Lam., Sterculiaceae, was collected in December 2004, in the city of Ibiporã, State of Paraná, Brazil (S 23¹8'15.2"; W 05058' 32.7"; 396 m altitude; Garmin v.2.24). The species was identified by Prof. Dr. Cássia Mônica Sakuragui. Voucher specimens are deposited in the Herbarium of the Department of Biology of the State University of Maringá under number HUM 10.491. This species occurs in the Amazonian region.

\section{Isolation and purification}

Air-dried stem bark (2000 g) was exhaustively extracted with $\mathrm{Me}_{2} \mathrm{CO}-\mathrm{H}_{2} \mathrm{O}(7: 3 ; 20 \mathrm{~L})$ by turbo-extraction (Ultra-turrax ${ }^{\circledR}$ UTC115KT; $20 \mathrm{~min} ; \mathrm{t} \leq 40{ }^{\circ} \mathrm{C}$ ), and the combined extracts were filtered and evaporated under reduced pressure to 1.0 L and lyophilized (229.6 g, CE). 
$200 \mathrm{~g}$ of this fraction was redissolved in $2.5 \mathrm{~L} \mathrm{H}_{2} \mathrm{O}$ and extracted with EtOAc (35 L). After evaporation of solvents, the EtOAc fraction (GU) and the remaining $\mathrm{H}_{2} \mathrm{O}$ phase (GU-1) gave dark-brown solids of 24 and $174 \mathrm{~g}$, respectively. A portion $(19 \mathrm{~g})$ of the $\mathrm{GU}$ fraction was subjected to $\mathrm{CC}$ on Sephadex LH-20 [710×50 mm; eluents: $20 \% \mathrm{EtOH}$ (3.2 L), 30\% EtOH (1.8 L), 40\% EtOH (4.8 L), 50\% EtOH (3.9 L), 100\% EtOH (1.6 L), 50\% MeOH (2.3 L), and $70 \% \mathrm{Me}_{2} \mathrm{CO}(6 \mathrm{~L}) ; 10 \mathrm{~mL}$ fractions] afforded 29 fractions (indicated with Roman numerals). Fraction XII (706 mg) was separated by MLCCC, with the solvent system EtOAc-n-PrOH- $\mathrm{H}_{2} \mathrm{O}$ (35:2:2) on a P.C. Inc. ITO Multilayer Coil Separator-Extractor, flow rate $1.0 \mathrm{~mL} \mathrm{~min}$, using the upper layer as mobile phase, giving rise to 5 subfractions. A portion of subfraction XII-4 $(31 \mathrm{mg})$ was acetylated and purified by preparative TLC to yield the peracetate resulting in epigallocatechin $(1.4 \mathrm{mg})$ and ent-gallocatechin $(2.2 \mathrm{mg})$ (these subfractions are indicated below by ordinal numbers). Fraction XIII (376 mg) was submitted to the MLCCC as mentioned above, giving rise to 5 subfractions. A portion of subfraction XIII-1 $(47.8 \mathrm{mg})$ was acetylated and purified by preparative TLC to yield the peracetate of 4'-O-methyl-epiafzelechin (2.2 mg) (9a). A portion of subfraction XIII-2 (123.1 mg) was acetylated and purified by preparative TLC to yield the peracetates of ent-catechin (14.2 mg) and epicatechin (13.1 mg). Fraction XIV (1156.5 mg) was separated on MLCCC as mentioned above, giving 5 subfractions. Subfraction XIV-1 $(8.1 \mathrm{mg})$ was acetylated and purified by preparative TLC to yield the peracetate of epicatechin- $(4 \beta \rightarrow 8)$-epigallocatechin $(4.9 \mathrm{mg})$. Subfraction XIV-2 $(198.1 \mathrm{mg})$ was acetylated and yielded epiafzelechin- $(4 \beta \rightarrow 8)$-epicatechin. Subfraction XIV-3 (711.2 mg) was acetylated and yielded epicatechin$(4 \beta \rightarrow 8)$-epicatechin (PB2). A portion of subfraction XIV-4 $(41 \mathrm{mg})$ was acetylated and purified by preparative TLC to yield the peracetate of epicatechin- $(4 \beta \rightarrow 8)$-catechin (PB1) (4.8 mg).

\section{General}

${ }^{1} \mathrm{H}$ NMR spectra were recorded in $\mathrm{CDCl}_{3}$ on a Varian Mercury 300BB (300 MHz) and Varian Inova (500 MHz) at ambient temperature with TMS as the internal standard. CD data were obtained in $\mathrm{MeOH}$ on a Jasco J-815. Polarimetry was measured with a Perkin-Elmer 241. An ESI-MS mass spectrometer, Quattro LCZ from Waters, was used in the positive-ion mode. Compounds were revealed by spraying with vanillin- $\mathrm{HCl}$ reagent and $1 \%$ ethanolic $\mathrm{FeCl}_{3}$ solution on TLC. Analytical TLC was carried out on precoated aluminum sheets (Kieselgel $60 \mathrm{~F}_{254}, 0.2 \mathrm{~mm}$, Merck) using EtOAc:HCOOH:H$: \mathrm{H}_{2} \mathrm{O}$ (90:5:5). Preparative TLC was performed on silica-gel plates (Kieselgel $60 \mathrm{~F}_{254}, 0.5 \mathrm{~mm}$, Merck) using toluene: $\mathrm{Me}_{2} \mathrm{CO}$ (60:40). Acetylation was performed in pyridine- $\mathrm{Ac}_{2} \mathrm{O}(1: 1.2)$ at ambient temperature for $24 \mathrm{~h}$.

\section{Compound identification}

ent-Catechin (1): ESI-MS m/z $313.1[\mathrm{M}+\mathrm{Na}]^{+}$; $[\alpha]_{\mathrm{D}}^{20}-20.1^{\circ}($ c $0.02, \mathrm{MeOH}) ;{ }^{1} \mathrm{H} \mathrm{NMR}\left(300 \mathrm{MHz} ; \mathrm{CDCl}_{3}\right)$ : $\delta$ 1.25-2.30 (5xOAc, m); 2.66 [1H, dd, $J 16.8,6.6, \mathrm{H}-4 \beta$ (C)]; 2.87 [1H, dd, $J 16.8,5.1, \mathrm{H}-4 \alpha(\mathrm{C})] ; 5.15[1 \mathrm{H}, \mathrm{d}, J$ 8.9, H-2 (C)]; 5.25 [1H, ddd, J 8.9, 6.6, 5.1, H-3 (C)]; 6.59 [1H, d, J 2.1, H-6 (A)]; 6.66 [1H, d, J 2.1, H-8 (A)]; 7.17 [1H, d, J 8.1, H-5' (B)]; 7.28 [1H, dd, J 8.1, 2.1, H-6' (B)]; 7.28 [1H, d, $\left.J 2.1, \mathrm{H}^{\prime} 2^{\prime}(\mathrm{B})\right]$.

Epicatechin (2): ESI-MS m/z $313.2[\mathrm{M}+\mathrm{Na}]^{+}$; $[\alpha]_{\mathrm{D}}^{20}-42^{\circ}(c 0.004, \mathrm{MeOH}) ;{ }^{1} \mathrm{H} \mathrm{NMR}\left(300 \mathrm{MHz} ; \mathrm{CDCl}_{3}\right)$ : $\delta$ 1.25-2.30 (5xOAc, m); 2.87 [1H, dd, $J$ 17.7, 2.1, H-4 $\beta$

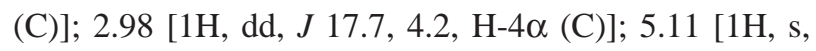
$J<1, \mathrm{H}-2$ (C)]; 5.39 [1H, m, $J<1, \mathrm{H}-3$ (C)]; 6.57 [1H, d, $J$ 2.1, H-6 (A)]; 6.67 [1H, d, J 2.1, H-8 (A)]; 7.20 [1H, d, $J$ 8.4, H-5' (B)]; 7.27 [1H, dd, $J$ 8.4, 1.8, H-6' (B)]; 7.36 [1H, d, J 1.8, H-2' (B)].

ent-Gallocatechin (3): ESI-MS m/z $329.3[\mathrm{M}+\mathrm{Na}]^{+}$; $[\alpha]_{\mathrm{D}}^{20}-16.8^{\circ}$ ( $\left.c 0.005, \mathrm{MeOH}\right) ;{ }^{1} \mathrm{H} \mathrm{NMR}\left(300 \mathrm{MHz} ; \mathrm{CDCl}_{3}\right)$ : $\delta$ 1.25-2.30 (6xOAc, m); 2.66 [1H, dd, $J$ 16.8, 6.6, H-4 $\beta$ (C)]; 2.91 [1H, dd, $J 16.8,5.1, \mathrm{H}-4 \alpha(\mathrm{C})] ; 5.12[1 \mathrm{H}, \mathrm{d}, J$ 6.3, H-2 (C)]; 5.21 [1H, ddd, J 6.6, 6.3, 5.1, H-3 (C)]; 6.60 [1H, d, J 2.1, H-6 (A)]; 6.66 [1H, d, J 2.1, H-8 (A)]; 7.12 [1H, s, H-2'/H-6' (B)].

Epigallocatechin (4): ESI-MS m/z $329.1[\mathrm{M}+\mathrm{Na}]^{+}$; $[\alpha]_{\mathrm{D}}^{20}-30^{\circ}(c 0.02, \mathrm{MeOH}) ;{ }^{1} \mathrm{H} \mathrm{NMR}\left(300 \mathrm{MHz} ; \mathrm{CDCl}_{3}\right): \delta$

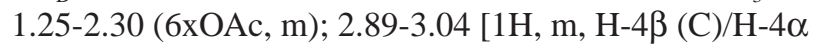
(C)]; 5.09 [1H, s, H-2 (C)]; 5.38 [1H, m, H-3 (C)]; 6.57 [1H, d, J 2.1, H-6 (A)]; 6.67 [1H, d, J 2.1, H-8 (A)]; 7.23 [1H, s, H-2/H-6' (B)].

Epiafzelechin-( $4 \beta \rightarrow 8)$-epicatechin (5): ESI-MS $\mathrm{m} / \mathrm{z} 963.2[\mathrm{M}+\mathrm{Na}]^{+} ; \mathrm{CD}(\mathrm{MeOH}):[\Theta]_{240}=+13,000$ $[\Theta]_{280}=-6,500 ;[\alpha]_{\mathrm{D}}^{20}+12^{\circ}(c 0.001, \mathrm{MeOH}) ;{ }^{1} \mathrm{H}$ NMR $\left(500 \mathrm{MHz} ; \mathrm{CDCl}_{3}\right.$ ): $\delta$ 1.25-2.30 (9xOAc, $\mathrm{m}$ ); 2.87-2.91

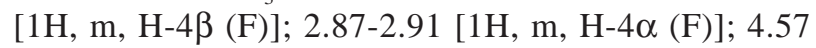
$[1 \mathrm{H}, \mathrm{s}, \mathrm{H}-2(\mathrm{~F})] ; 4.44[1 \mathrm{H}, \mathrm{d}, \mathrm{H}-4(\mathrm{C})] ; 5.17[1 \mathrm{H}, \mathrm{m}$, H-3 (F)]; 5.19 [1H, m, H-3 (C)]; 5.60 [1H, s, H-2 (C)]; $6.00[1 \mathrm{H}, \mathrm{d}, J 2.1, \mathrm{H}-6$ (A)]; 6.22 [1H, d, J 2.1, H-8 (A)]; 6.62 [1H, s, H-6 (D)]; 6.90-7.40- [2H, m, H2'/H5'/H6' (E)]; 7.42 [2H, d, $J$ 8.7, H-2/H-6' (B)]; 7.14 [2H, d, $J$ 8.7, H-3/H-5' (B)]. 
Epicatechin- $(4 \beta \rightarrow 8)$-catechin (PB1) (6): ESI-MS $\left[\mathrm{M}+\mathrm{Na}^{+}\right]^{+} m / z$ 1021.5; $\left[\mathrm{M}-\mathrm{H}^{+}\right]^{-} m / z$ 997.5; $[\alpha]_{\mathrm{D}}^{20}+2.2^{\circ}$ (c $0.002, \mathrm{MeOH}) ;{ }^{1} \mathrm{H}$ NMR (300 MHz; $\mathrm{CDCl}_{3}$ ): $\delta 1.25-$ 2.33 (10xOAc, m); 2.56 [1H, dd, $J$ 16.8, 9.3, H-4ß (F)];

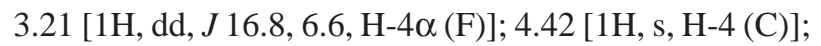
$4.33[1 \mathrm{H}, \mathrm{d}, J 9.9, \mathrm{H}-2$ (F)]; 5.05 [1H, ddd, $J$ 9.9, 9.3, 6.6, H-3 (F)]; 5.15 [1H, m, H-3 (C)]; 5.45 [1H, s, H-2 (C)]; 5.99 [1H, d, $J 2.1, \mathrm{H}-6$ (A)]; 6.29 [1H, d, $J$ 2.1, H-8 (A)]; $6.68[1 \mathrm{H}, \mathrm{s}, \mathrm{H}-6$ (D)]; 7.16 [1H, d, $J$ 8.4, H-5 (B)]; $7.25\left[1 \mathrm{H}, \mathrm{dd}, J 8.4,1.8, \mathrm{H}-6^{\prime}\right.$ (B)]; $6.88[1 \mathrm{H}, \mathrm{d}, J 1.8, \mathrm{H}-2$ ' (B)]; 6.95 [1H, d, J 8.4, H-5' (E)].

Epicatechin-(4 $\beta \rightarrow 8)$-epicatechin (PB2) (7): ESI-MS $\left[\mathrm{M}+\mathrm{Na}^{+}\right]^{+} m / z$ 1021.5; $\left[\mathrm{M}-\mathrm{H}^{+}\right]^{-} m / z$ 997.5; $[\alpha]_{\mathrm{D}}^{20}+4.5^{\circ}$ (c $0.002, \mathrm{MeOH}) ;{ }^{1} \mathrm{H} \mathrm{NMR}\left(500 \mathrm{MHz} ; \mathrm{CDCl}_{3}\right): \delta 1.25-2.33$

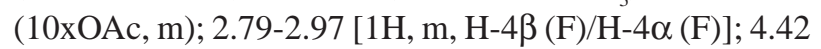
[1H, s, H-4 (C)]; $4.51[1 \mathrm{H}, \mathrm{s}, \mathrm{H}-2(\mathrm{~F})] ; 5.07[1 \mathrm{H}, \mathrm{m}, \mathrm{H}-3$ (F)]; $5.13[1 \mathrm{H}, \mathrm{m}, \mathrm{H}-3(\mathrm{C})]$; 5.54 [1H, s, H-2 (C)]; $5.95[1 \mathrm{H}$, d, $J 1.5, \mathrm{H}-6$ (A)]; 6.19 [1H, d, J 1.5, H-8 (A)]; $6.62[1 \mathrm{H}$, s, H-6 (D)]; 6.85 [1H, dd, J 8.5, 2.0, H-6' (E)]; $6.98[1 \mathrm{H}$, d, J 2.0, H-2' (E)]; 6.99 [1H, d, J 8.5, H-5' (E)]; 7.14 [1H, d, $J$ 8.5, H-5' (B)]; 7.32 [1H, d, $J$ 2.0, H-2' (B)].

Epicatechin- $(4 \beta \rightarrow 8)$-epigallocatechin $(\mathbf{8})$ : ESI-MS $\left[\mathrm{M}+\mathrm{Na}^{+}\right]^{+} m / z$ 1079.4; $\left[\mathrm{M}-\mathrm{H}^{+}\right]^{-} m / z$ 997.5; $[\alpha]_{\mathrm{D}}^{20}+22^{\circ}$ (c $0.002, \mathrm{MeOH}) ;{ }^{1} \mathrm{H} \mathrm{NMR}\left(300 \mathrm{MHz} ; \mathrm{CDCl}_{3}\right): \delta 1.25-2.33$ (11xOAc, m); $2.90[1 \mathrm{H}, \mathrm{m}, \mathrm{H}-4 \beta(\mathrm{F}) / \mathrm{H}-4 \alpha(\mathrm{F})] ; 4.47[1 \mathrm{H}, \mathrm{m}$, H-4 (C)]; 4.51 [1H, s, H-2 (F)]; 5.10 [1H, m, H-3 (F)]; 5.14 [1H, m, H-3 (C)]; 5.57 [1H, s, H-2 (C)]; 6.06 [1H, d, J 2.4, H-6 (A)]; 6.25 [1H, d, J 2.4, H-8 (A)]; 6.65 [1H, s, H-6 (D)]; 7.36 [1H, d, $J$ 1.8, H-2' (B)]; 7.17 [1H, d, $J$ 8.4, H-5' (B)]; 7.25 [1H, dd, J 8.4, 1.8, H-6' (B)]; 6.89 [1H, s, H-2/H-6' (E)].

4'-O-Methyl-epiafzelechin (9a): ESI-MS m/z 437.5 $[\mathrm{M}+\mathrm{Na}]^{+} ; \mathrm{CD}(\mathrm{MeOH}):[\Theta]_{240}=+13,000$ and $[\Theta]_{280}=-8,800$; $[\alpha]_{\mathrm{D}}^{20}+22^{\circ}(c 0.002, \mathrm{MeOH}) ;{ }^{1} \mathrm{H} \mathrm{NMR}\left(300 \mathrm{MHz} ; \mathrm{CDCl}_{3}\right)$ :

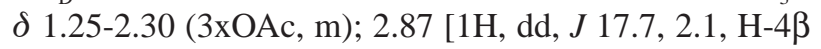

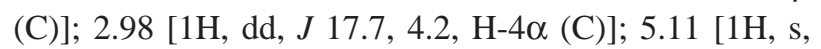
$J<1, \mathrm{H}-2(\mathrm{C})] ; 5.39$ [1H, m, $J<1, \mathrm{H}-3$ (C)]; 6.57 [1H, d, $J$ 2.1, H-6 (A)]; 6.67 [1H, d, J 2.1, H-8 (A)]; 7.20 [1H, d, $J$ 8.4, H-5' (B)]; 7.27 [1H, dd, $J$ 8.4, 1.8, H-6' (B)]; $7.36\left[1 \mathrm{H}, \mathrm{d}, J 1.8, \mathrm{H}-2^{\prime}\right.$ (B)].

\section{HPLC characterization}

\section{Chemicals and reagents}

All reagents and solvents were analytical or HPLC grade, including the ethyl acetate and trifluoroacetic acid (TFA) (Merck, Germany). Ultra-pure water obtained using a Milli-Q ${ }^{\circledR}$ UF-Plus apparatus (Millipore, USA) was used in all experiments.

\section{Instrumentation and chromatographic conditions}

The analyses were carried out using a HPLC system (Gilson, USA) consisting of a solvent delivery pump (Model 321), a variable wavelength UV/Vis detector (Model 156), a manual injection valve (Rheodyne ${ }^{\circledR}$, USA) with a $20 \mu \mathrm{L}$ loop, degasser (Model 184), and a thermostatted column compartment (Model 831). Data collection and analyses were performed using UniPoint ${ }^{\mathrm{TM}}$ LC System Software (Gilson, France). Gradient elution was performed on a Phenomenex ${ }^{\circledR}$ Gemini RP C-18 column (250 mm x $4.6 \mathrm{~mm}$ ) (Phenomenex International, USA), $5 \mu \mathrm{m}$ particle size with a Phenomenex ${ }^{\circledR}$ SecurityGuard $^{\mathrm{TM}}$ (RP C-18 cartridge) (20 mm x $4.6 \mathrm{~mm})$. The mobile phase consisted of water $(0.05 \%$ TFA) as solvent A and acetonitrile ( $0.05 \%$ TFA) as solvent $\mathrm{B}$, and both were degassed and filtered through a $0.45 \mu \mathrm{m}$ pore-size filter (Millipore, USA). Separations were effected by a linear gradient as follows: 0 min $13 \% \mathrm{~B} ; 10 \mathrm{~min}$ $17 \%$ B $16 \min 19.35 \%$ B $; 20 \min 22.65 \%$ B $; 23 \min 29.81 \%$ B; $25 \min 65 \%$ B; $28 \min 13 \%$ B; and $32 \min 13 \%$ B. The mobile-phase flow rate was $0.8 \mathrm{~mL} \mathrm{~min}^{-1}$ and the injection volume was $100 \mu \mathrm{L}$. The chromatographic runs were carried out at $28^{\circ} \mathrm{C}$. UV detection was performed at $210 \mathrm{~nm}$.

For the determination of peak purity, the Varian ProStar module (Varian, USA) with ProStar 210 Solvent Delivery and a ProStar 335 HPLC-DAD was used.

\section{Sample preparation and purification}

An accurately weighed portion of $50 \mathrm{mg}$ of the $\mathrm{CE}$ was dissolved in $500 \mu \mathrm{L}$ water, mixed in a tube shaker, and extracted with $500 \mu \mathrm{L}$ ethyl acetate, in a microtiter shaker at $1800 \mathrm{rpm}\left(\mathrm{IKA}^{\circledR}\right.$, MS1 Minishaker) for $3 \mathrm{~min}(\mathrm{n}=6)$. The tubes were then placed in a refrigerated microcentrifuge (Eppendorf $^{\circledast}$, Centrifuge 5415R), at 4,000 rpm, for the total separation of the phases, for 4 min at $5{ }^{\circ} \mathrm{C}$. The ethyl acetate phase was separated. After evaporation of solvents, and drying under air flow, the residue was reconstituted to $10 \mathrm{~mL}$ with methanol:water $(1: 1 ; \mathrm{v} / \mathrm{v})$ (Solution test-SS). The sample was filtered through a $0.5 \mu \mathrm{m}$ membrane filter (Millipore, USA). The sample injection volume was $100 \mu \mathrm{L}$.

\section{Acknowledgements}

The authors are grateful for financial support from CAPES, FINEP and CNPq. We gratefully acknowledge the recording of NMR spectra by Dr. Ivânia Terezinha Albrecht Schuquel (Department of Chemistry, State University of Maringá). Dr. Heinrich Luftmann (Institute of Organic Chemistry, Münster, Germany) recorded the ESI-mass spectra. We are also grateful to Dr. Janet W. Reid for revising the English text. 


\section{Supplementary Information}

NMR spectral data of compounds 1-9 are available free of charge at http://jbcs.sbq.org.br, as PDF file.

\section{References}

1. Becker, B. K.; Estud. av. 2005, 19, 71.

2. Begossi, A.; Econ. Bot. 1996, 50, 280.

3. Lévêque, C.; A Biodiversidade, 1a ed., EDUSC: São Paulo, Brasil, 1999.

4. Arruda, A. C.; T\&C Amazon. 2008, 14, 23.

5. Macari, P. A. T.; Portela, C. N.; Pohlit, A. M.; Acta Amaz. 2006, 36, 513.

6. Veiga Junior, V. F.; Andrade Junior, M. A.; Ferraz, I. D. K.; Christo, H. B.; Pinto, A. C.; Acta Amaz. 2007, 37, 123.

7. Yamaguti-Sasaki, E.; Ito, L. A.; Canteli, V. C. D.; Ushirobira, T. M. A.; Ueda-Nakamura, T.; Dias Filho, B. P.; Nakamura, C. V.; Mello, J. C. P.; Molecules 2007, 12, 1950.

8. Veiga Junior, V. F.; Rosas, E. C.; Carvalho, M. V.; Henriques, M. G. M. O.; Pinto, A. C.; J. Ethnopharmacol. 2007, 112, 248.

9. Mendes, F. R.; Carlini, E. A.; J. Ethnopharmacol. 2007, 109, 493.

10. Barbosa, J. M.; Macedo, A. C.; Instituto de Botânica e Fundação Florestal, São Paulo, Brasil, 1993, p. 125.

11. Lorenzi, H.; Árvores Brasileiras: Manual de Identificação e Cultivo de Plantas Arbóreas Nativas do Brasil, Instituto Plantarum, Nova Odessa, São Paulo, Brasil, 1992.

12. Rodrigues, E.; J. Ethnopharmacol. 2007, 111, 295.

13. Cáceres, A.; Giron, L. M.; Martinez, A. M.; J. Ethnopharmacol. 1987, 19, 233

14. Cáceres, A.; Cano, O.; Samayoa, B.; Aguilar, L.; J. Ethnopharmacol. 1990, 30, 55.

15. Cáceres, A.; Torres, M. F.; Ortiz, S.; Cano, F.; Jauregui, E.; J. Ethnopharmacol. 1993, 39, 77.

16. Weniger, B.; Rouzier, M.; Daguilh, R.; Henrys, D.; Henrys, J. H.; Anton, R.; J. Ethnopharmacol. 1986, 17, 13.

17. Domínguez, X. A.; Alcorn, J. B.; J. Ethnopharmacol. 1985, 13, 139.

18. Heinrich, M.; Rimpler, H.; Barrera, N. A.; J. Ethnopharmacol. 1992, 36, 63.

19. Heinrich, M.; Curr. Top. Med. Chem. 2003, 3, 141.

20. Camporese, A.; Balick, M. J.; Arvigo, R.; Esposito, R. G.; Morsellino, N.; De Simone, F.; Tubaro, A.; J. Ethnopharmacol. 2003, 87, 103 .

21. Hör, M.; Heinrich, M.; Rimpler, H.; Phytochemistry 1996, 42, 109.
22. Seigler, D. S.; Pauli, G. F.; Fröhlich, R.; Wegelius, E.; Nahrstedt, A.; Glander, K. E.; Ebinger, J. E.; Phytochemistry 2005, 66, 1567.

23. Alarcon-Aguilara, F. J.; Romam-Ramos, R.; Perez-Gutierrez, S.; Aguilar-Contreras, A.; Contreras-Weber, C. C.; Flores-Saenz, J. L.; J. Ethnopharmacol. 1998, 61, 101.

24. Caballero-George, C.; Vanderheyden, P. A.; De Bruyne, T.; Shahat, A. A.; Van Den Heuvel, H.; Solis, P. N.; Gupta, M. P.; Claeys, M.; Pieters, L.; Vauqueli, G.; Vlietinck, A. J.; Planta Med. 2002, 68, 1066.

25. Hör, M.; Rimpler, H.; Heinrich, M.; Planta Med. 1995, 61, 208.

26. Berenguer, B.; Trabadela, C.; Sánchez-Fidalgo, S.; Quílez, A.; Miño, P.; De la Puerta, R.; Martín-Calero, M. J.; J. Ethnopharmacol. 2007, 114, 153.

27. Navarro, M. C.; Montilla, M. P.; Cabo, M. M.; Galisteo, M.; Cáceres, A.; Morales, C.; Berger, I.; Phytother. Res. 2003, 17, 325 .

28. Felipe, A. M. M.; Rincão, V. P.; Benati, F. J.; Linhares, R. E.; Galina, K. J.; Toledo, C. E. M.; Lopes, G. C.; Mello, J. C. P.; Nozawa, C.; Biol. Pharm. Bull. 2006, 29, 1092.

29. Weinges, K.; Göritz, K.; Nader, F.; Liebigs Ann. Chem. 1968, 715,164

30. Thompson, R. S.; Jacques, D.; Haslam, E.; Tanner, R. J. N.; J. Chem. Soc. Perkin Trans. I 1972, 1387.

31. Fletcher, A. C.; Porter, L. J.; Haslam, E.; Gupta, R. K.; J. Chem. Soc. Perkin Trans. I 1977, 1628.

32. Kolodziej, H.; Phytochemistry 1986, 25, 1209.

33. Kolodziej, H.; Farm. Tijdschr. Belg. 1989, 66, 44.

34. Outtrup, H.; Schaumburg, K.; Carlsberg Res. Commun. 1981, 46,3 .

35. Petereit, F.; Kolodziej, H.; Nahrstedt, A.; Phytochemistry 1991, 30, 981.

36. Mello, J. C. P.; Petereit, F.; Nahrstedt, A.; Phytochemistry 1996, $41,807$.

37. Foo, L. Y.; Lu, Y.; Howell, A. B.; Vorsa, N.; Phytochemistry 2000, 54, 173.

38. Dalluge, J. J.; Nelson, B. C.; Thomas, J. B.; Sander, L. C.; J. Chromatogr. A 1998, 793, 265.

39. Zhu, Q. Y.; Zhang, A.; Tsang, D.; Huang, Y.; Chen, Y. Z.; J. Agric. Food Chem. 1997, 45, 4624.

40. ICH. Analytical Validation Q2(R1), 2005. http://www.ich.org, accessed in June 2007.

Received: February 3, 2009 Web Release Date: June 26, 2009 


\section{Condensed Tannins from the Bark of Guazuma ulmifolia Lam. (Sterculiaceae)}

\section{Gisely C. Lopes, ${ }^{a}$ Juliana C. B. Rocha, ${ }^{a}$ Glalber C. de Almeida ${ }^{b}$ and João C. P. de Mello ${ }^{* a}$}

a'Programa de Pós-graduação em Ciências Farmacêuticas, Universidade Estadual de Maringá, Av. Colombo, 5790, 87020-900 Maringá-PR, Brazil

${ }^{b}$ Acadêmico de Farmácia, Universidade Estadual de Maringá, Av. Colombo, 5790, 87020-900 Maringá-PR, Brazil

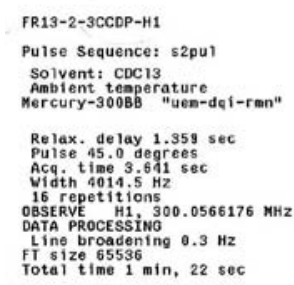

FR13-2-3CCOP-H1

Pulse Sequence: s2pul

Relax. de lay $1.359 \mathrm{sec}$

Act. time 3.641 sec

16 repetitions 0565176 NH:

tine broacening $0.3 \mathrm{~Hz}$

Total time 1 min, 22 sec

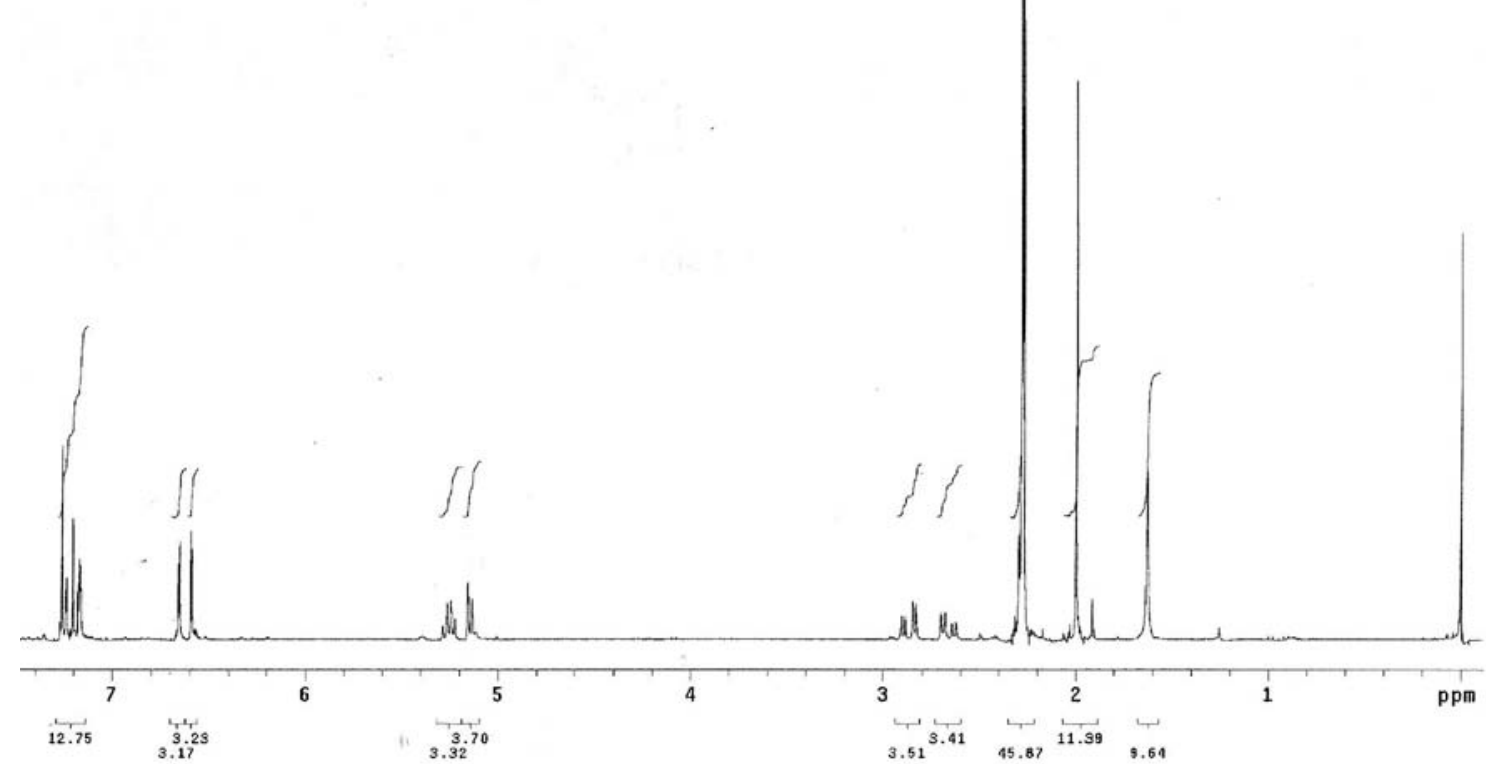

Figure S1. ${ }^{1} \mathrm{H}$ NMR spectrum of ent-catechin. 


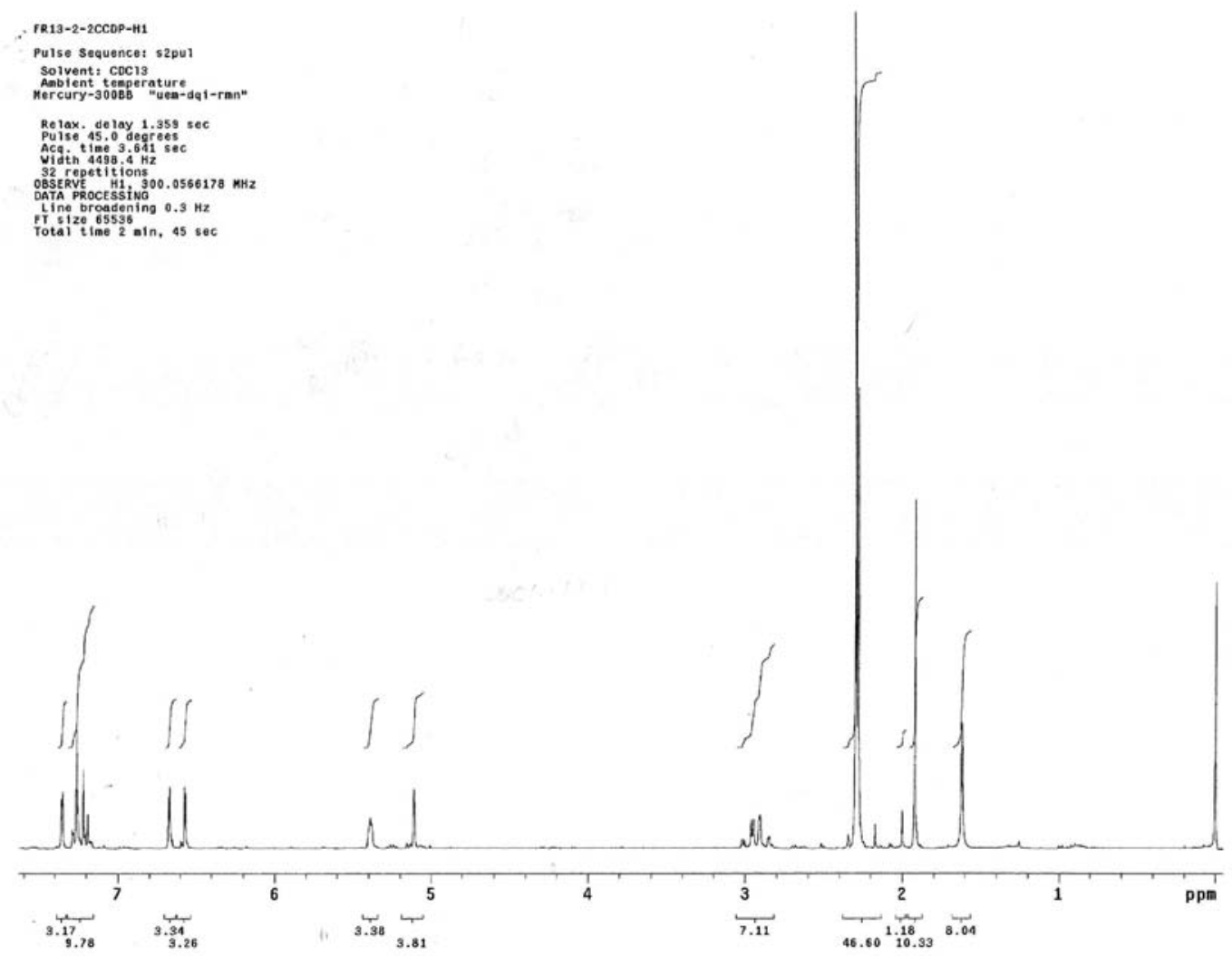

Figure S2. ${ }^{1} \mathrm{H}$ NMR spectrum of epicatechin.

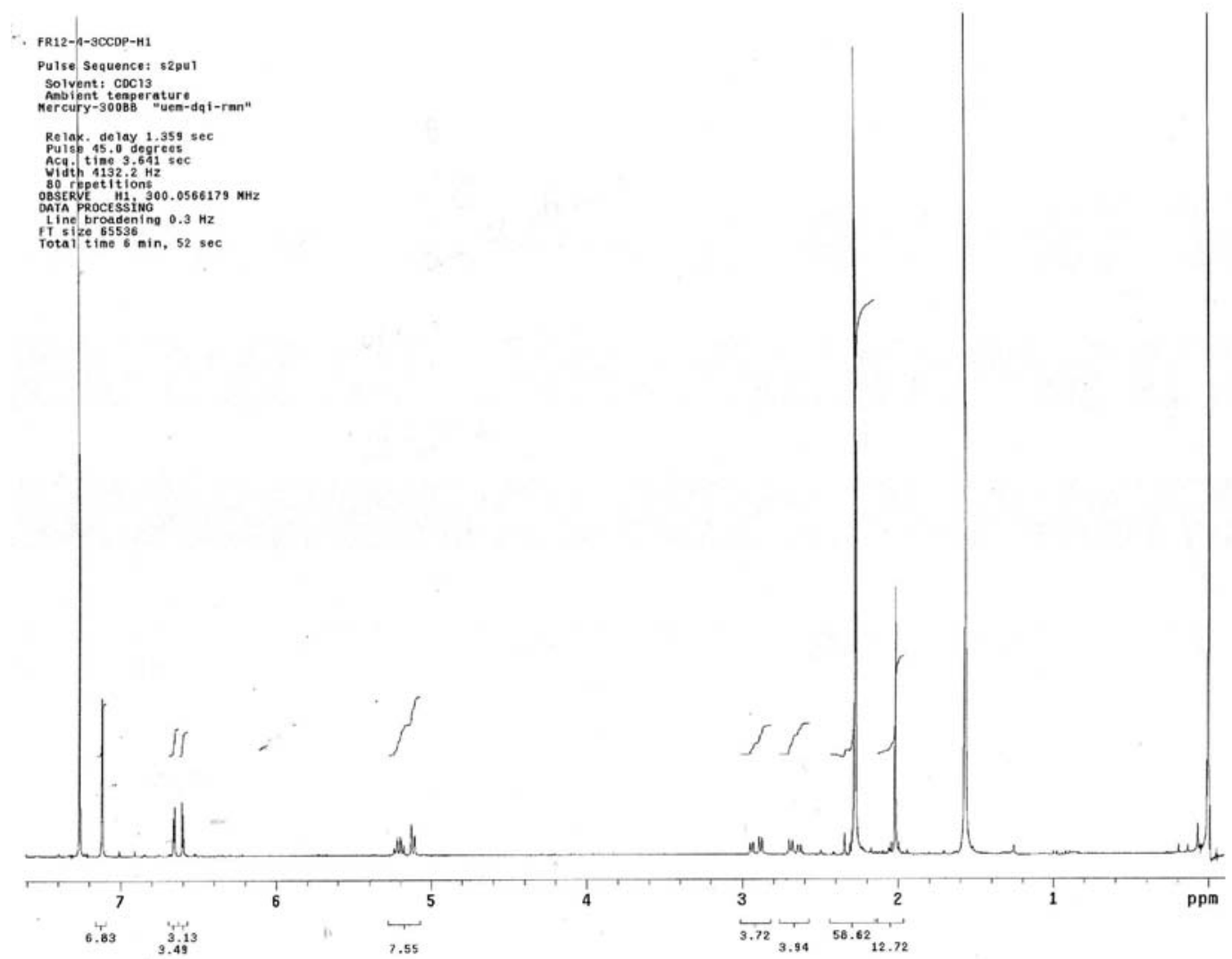

Figure S3. ${ }^{1} \mathrm{H}$ NMR spectrum of ent-gallocatechin. 


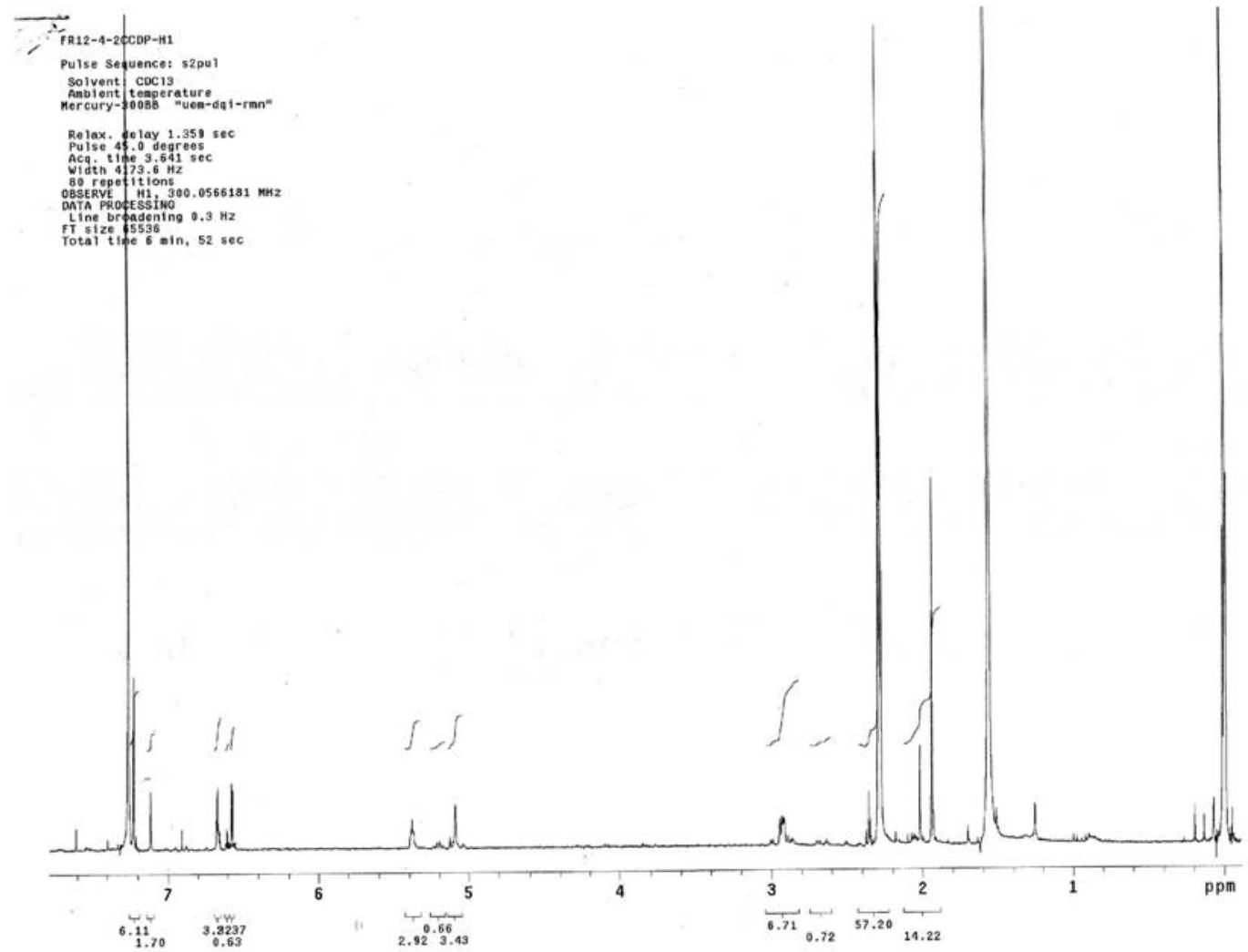

Figure S4. ${ }^{1} \mathrm{H}$ NMR spectrum of epigallocatechin.

Kb_su142_230904_298K_1h

$500 \mathrm{MHZ}$

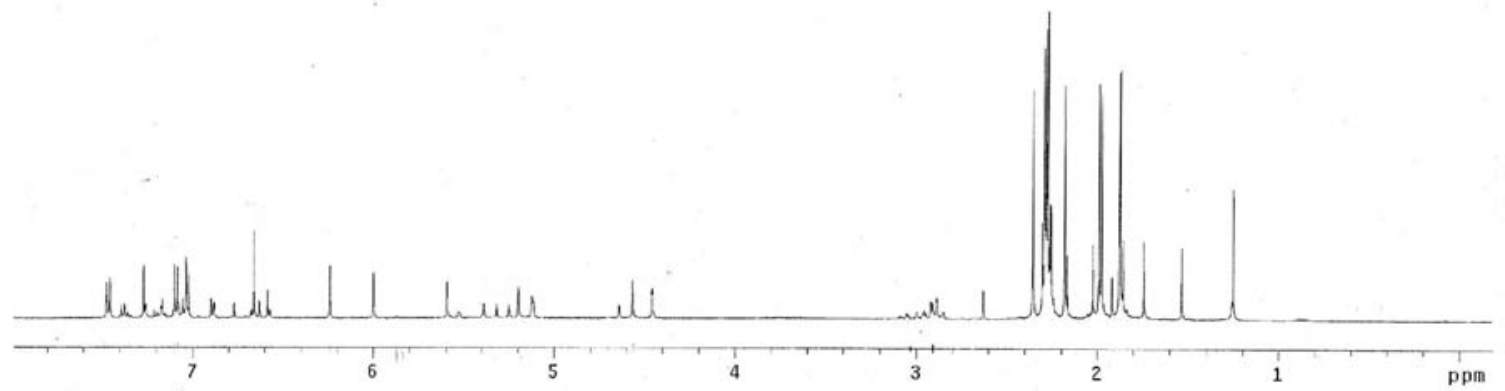

Figure S5. ${ }^{1} \mathrm{H}$ NMR spectrum of epiafzelechin- $(4 \beta \rightarrow 8)$-epicatechin. 


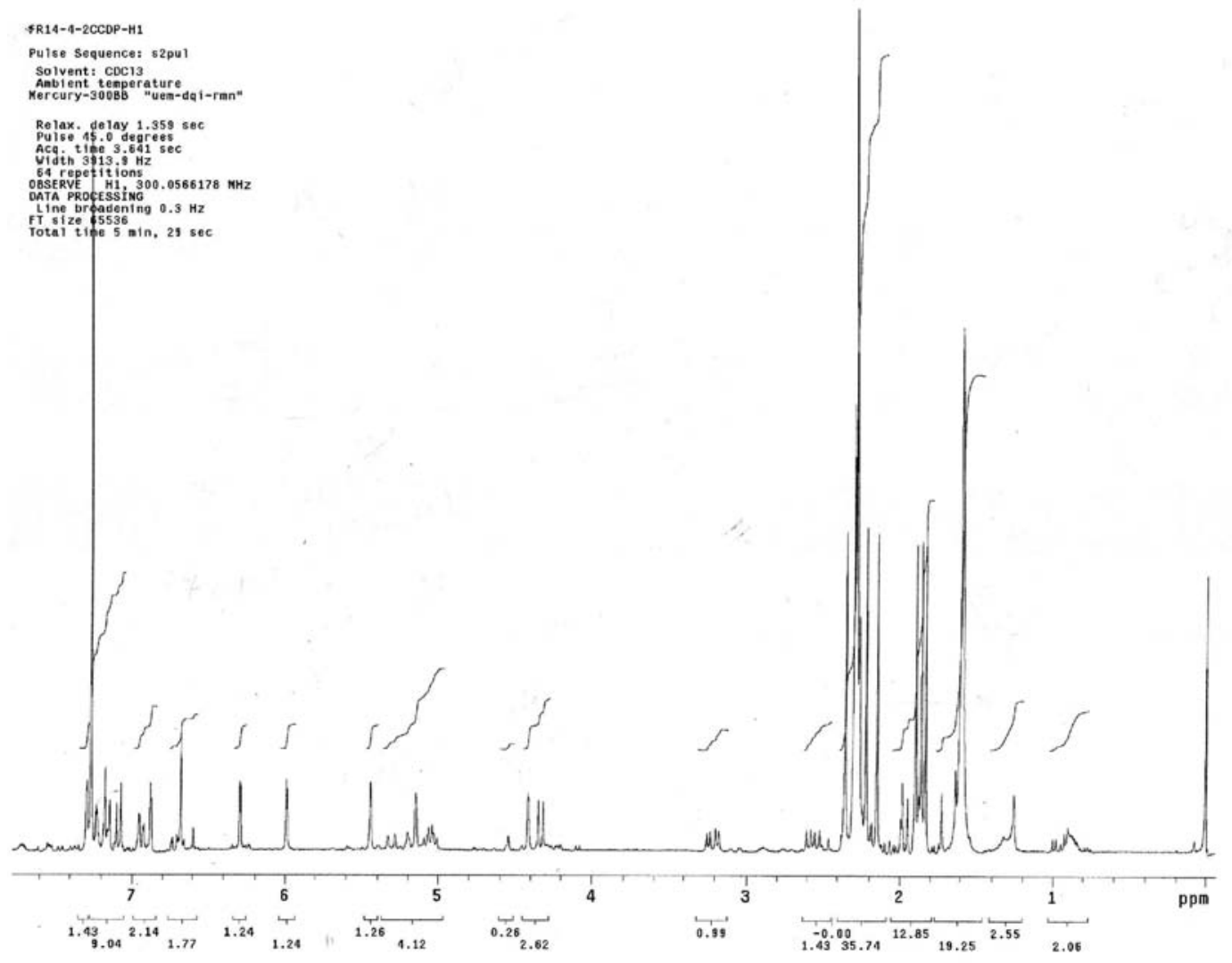

Figure S6. ${ }^{~} \mathrm{H}$ NMR spectrum of epicatechin- $(4 \beta \rightarrow 8)$-catechin.

Kb_au143_230904_298k_1h

$500 \mathrm{muz}$

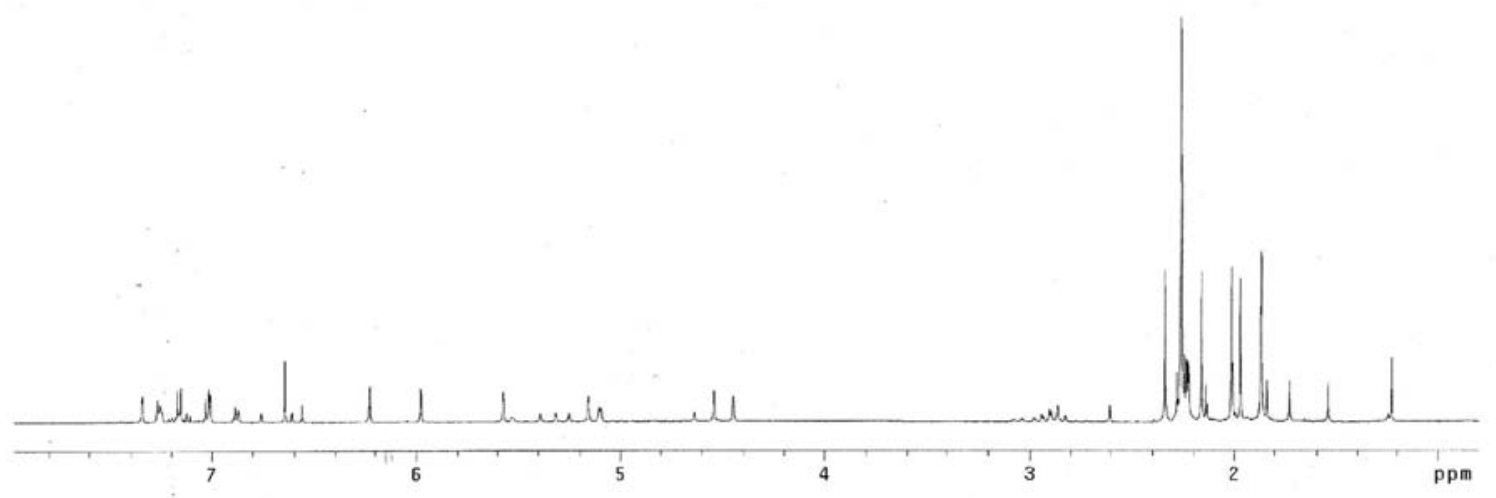

Figure S7. ${ }^{1} \mathrm{H}$ NMR spectrum of epicatechin- $(4 \beta \rightarrow 8)$-epicatechin. 


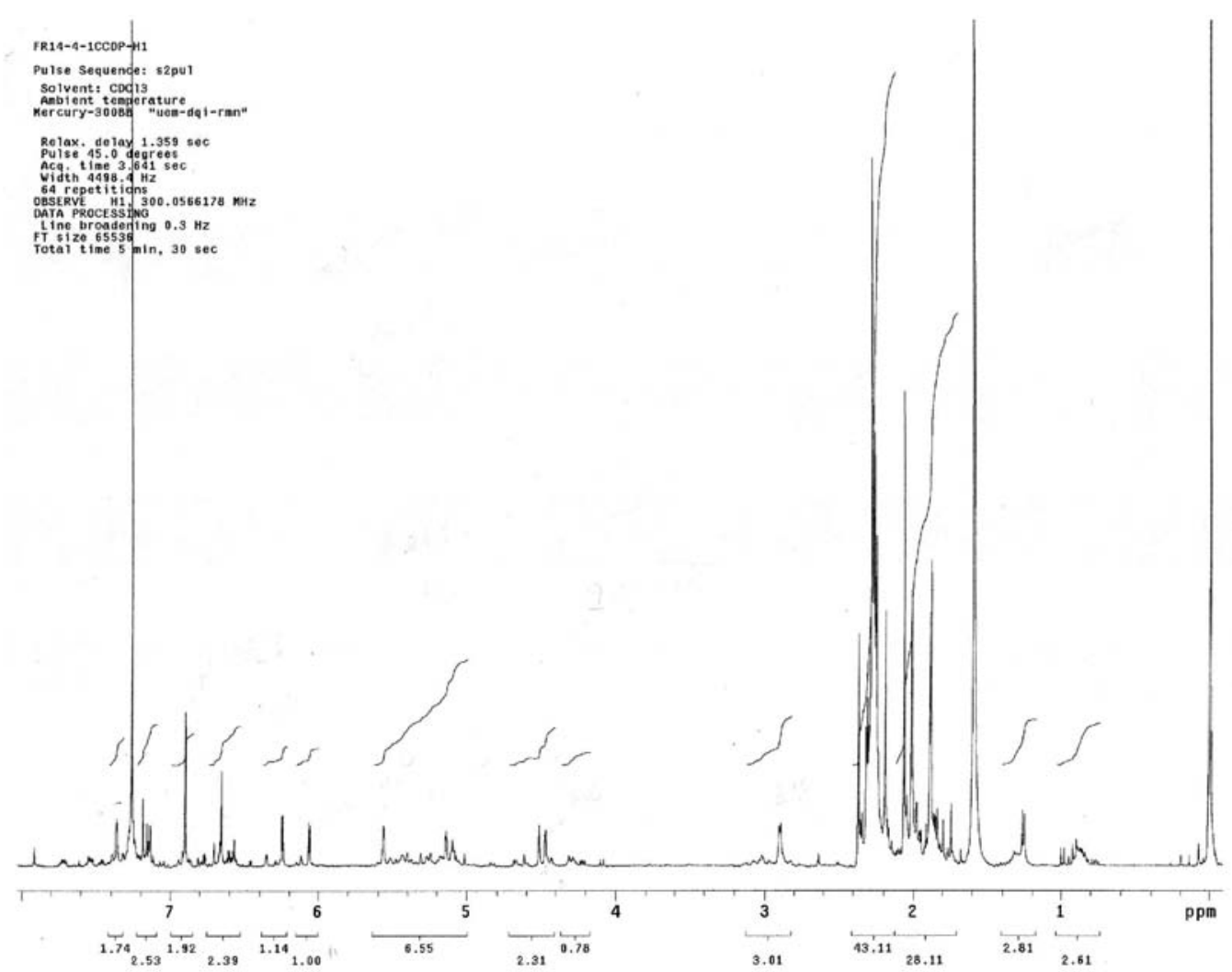

Figure S8. ${ }^{1} \mathrm{H}$ NMR spectrum of epicatechin-( $\left.4 \beta \rightarrow 8\right)$-epigallocatechin.

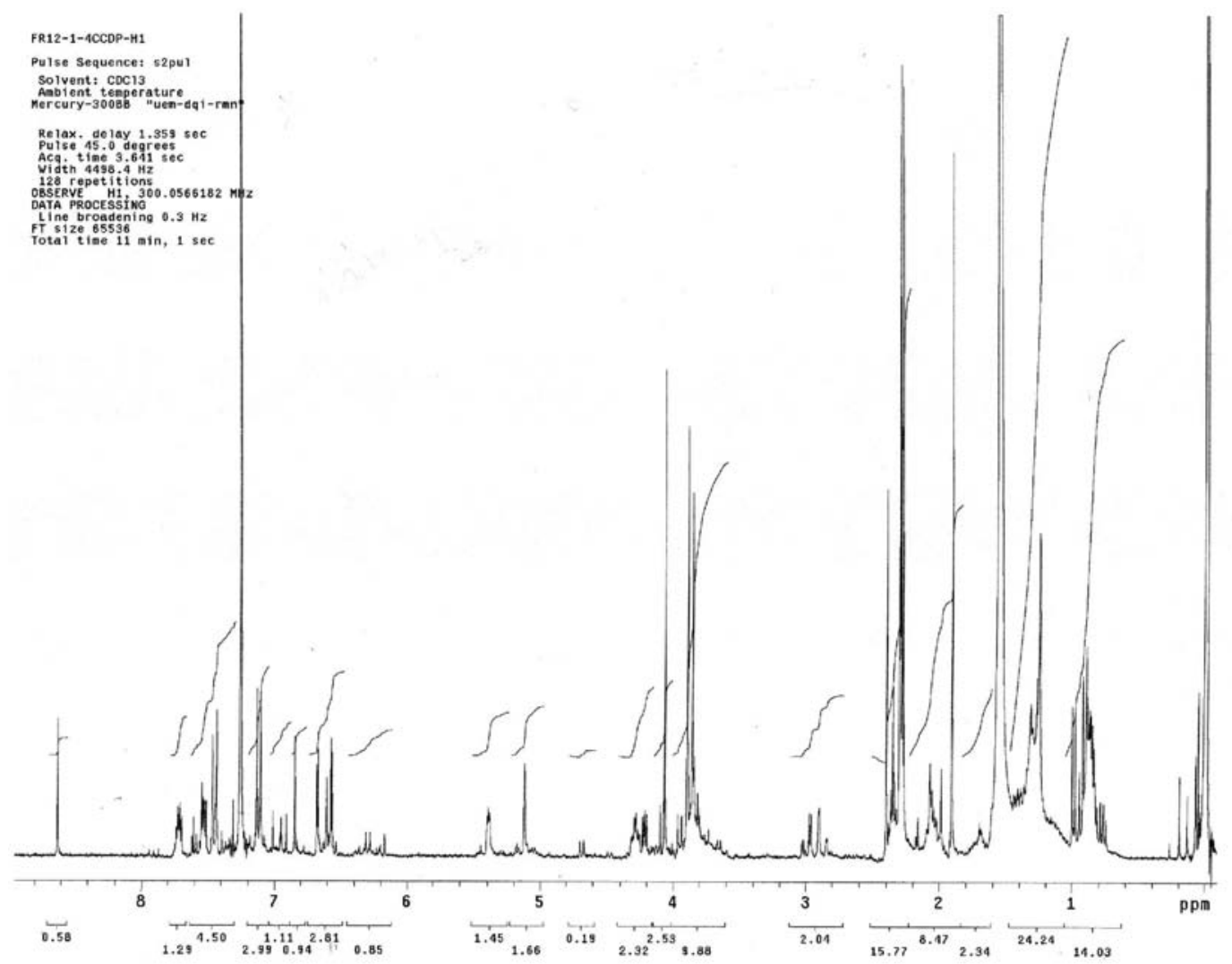

Figure S9. 'H NMR spectrum of 4'- $O$-methyl-epiafzelechin. 